\title{
Anaesthesia for ophthalmic surgery
}

Local anaesthesia for ophthalmic surgical procedures, of which more than $70 \%$ are cataract procedures, ${ }^{1}$ is commonplace. A recent audit on cataract surgery ${ }^{2}$ indicates that in the United Kingdom almost $50 \%$ of all cataract procedures are currently carried out under local anaesthesia. Local anaesthesia carries the potential for serious morbidity ${ }^{3-19}$ both from the administration of the local anaesthetic to the eye as well as from accompanying sedation of the patient.

Anaesthesia for ophthalmic surgery, however, is a complex issue; it does not simply mean 'is the patient asleep, awake, or sedated?' for the purpose of carrying out an ophthalmic operation. This issue is complex because the responsibility entailed embraces preoperative assessment of the patient, the mode of anaesthesia for surgery, monitoring of the patient during the surgical procedure, resuscitation of the patient should an adverse event occur, and immediate postoperative supervision of the patient's systemic status.

At the very least, anaesthesia in ophthalmology is a team affair in which surgeon, patient, anaesthetist, nurses, and technicians play their part. The initial decision on mode of anaesthesia for a particular procedure usually depends on patient choice (generally based on previous anaesthetic experience or the anecdotal experiences of relatives and friends). It is rarely an informed decision. The second criterion for choice of mode of anaesthesia is local circumstance. Is an anaesthetist available, efficient, and willing to play a full role in the team management of the patient? The third factor is the surgeon's experience and routine, for surgeons tend to be creatures of habit.

Most ophthalmic procedures can be performed under either general anaesthesia (GA) or local anaesthesia (LA). Like the term 'cataract surgery' GA and LA encompass a variety of approaches and techniques. GA, for example, may vary from a technique which utilises anaesthesia, muscle paralysis, and ventilation with intubation on the one hand, to propofol infusion, reliance on spontaneous breathing, and a laryngeal mask on the other. Both techniques and their variants are simplistically described as GA but their connotations for patient effect and recovery are quite different. Similarly, LA embraces retrobulbar, peribulbar, sub-Tenon, and topical methods of injecting varying amounts of anaesthetic agent into potentially dangerous places. In order to engage in serious debate on LA versus GA, specificity is required. There are, however, some general points that can be raised and these include principles of anaesthetic practice, personnel and areas of responsibility, economic (cost effectiveness) factors, geographic factors in relation to operating theatre suites, and common sense (medicolegal) considerations.

Although operations under a local anaesthetic are often performed in the absence of an anaesthetist the potential for complications cannot be ignored. ${ }^{3-19}$ It is not possible for surgeons to be responsible practically for monitoring a patient's general condition or be in a position to resuscitate a patient should the need arise, when they are required to concentrate on the delicate and demanding task of ophthalmic surgery.

Patient welfare is the overriding consideration in both the preparation and performance of an ophthalmic surgical procedure, with surgeon comfort and economic considerations following in that order. If that premise is accepted then areas of responsibility have to be defined and it would seem self-evident that ophthalmologists should concentrate their efforts on the eye. Some might claim that ophthalmologists are capable of divided responsibility during surgery. However, if there is an adverse event when surgery is at a critical stage and the ophthalmologist is the sole medical practitioner available, then the patient's best interests cannot be served. Nevertheless, the challenge is raised by many ophthalmologists relating to the thousands of operations under local anaesthesia which have never been associated with problems. They would further argue that if an anaesthetist is required to be present, then cost considerations will limit the quantity of surgery. The answer to this proposition is not easy to encapsulate for although the literature on adverse events in ophthalmic surgery is not extensive it is significant. ${ }^{3-19}$ It is probable that adverse events occur which are not reported because they are isolated.

There have been many changes in cataract surgery, particularly in recent years, often accepted following initial reluctance: extracapsular surgery, lens implantation, and now phacoemulsification some 25 years after its introduction. In cataract surgery, comfort with a longstanding technique eventually has to give way to progressive developments. So it should be with anaesthesia in ophthalmic surgery. The time of the team approach to anaesthesia is here. The decision on mode of anaesthesia to be employed in each case should be a team decision involving patient, surgeon, and anaesthetist. Evaluation of the physical condition of patients and the practice of anaesthesia should be the responsibility of the anaesthetist: this includes monitoring the patient's condition throughout surgery, management of complications, and postoperative recovery. In a recent study by Fisher and Cunningham ${ }^{21}$ the mean age of 100 patients was 75 and $84 \%$ had one or more serious systemic diseases: $47 \%$ had hypertension; $38 \%$ had ischaemic heart disease; $18 \%$ had a history of hypothyroidism; $16 \%$ had diabetes; and 3\% were diagnosed as having a new malignancy. Therefore preoperative assessment to diagnose and manage common and uncommon diseases occurring in patients before undergoing surgery is prudent.

Ophthalmic decisions and ophthalmic surgery are clearly the responsibility of the ophthalmologist. Other paramedical personnel are to be deployed as required under appropriate instruction. If several operating lists are taking place in conjoined theatres then an anaesthetist should be able to supervise these areas of activity with trained assistance and clearly defined areas of responsibility. Conversely, if ophthalmic surgery is taking place in an isolated operating theatre, the presence of an anaesthetist is essential and justified.

The College of Ophthalmologists, jointly with the Royal College of Anaesthetists, has issued agreed guidelines on best clinical practice in relation to ophthalmic surgery and anaesthesia. ${ }^{22}$ They conclude that our duty to practise safe surgery should encourage prevention as well as expert treatment of adverse events.

A team approach to ophthalmic surgery, whatever the mode of anaesthesia, may afford efficiencies in practice, with greater productivity offsetting the cost implications of change.

EMANUEL ROSEN

Manchester Cataract Centre at

Manchester Royal Eye Hospital,

Oxford Road,

Manchester M13 9WH 1 Manchester Royal Eye Hospital 1992 data. Cataract surgery as a proportion of

2 Courtney P. National cataract surgery survey. Eye 1992; 6: 487-92. 
3 Nicoll JMV, Acharya PA, Ahlen K, Baguneid S, Edge KR. Central nervous system complications after 6000 retrobulbar blocks. F Anaesth Anal 1987: 66-73.

4 Rosenblatt RM, May DR, Barsoumian K. Cardiopulmonary arrest after retrobulbar block. Am f Ophthalmol 1980; 90: 425-7.

5 Chang JL, Gonzales-Abola E, Larsen CE, Lobes L. Brain stem anaesthesia following retrobulbar block. Anaesthesiology 1984; 61: 789-90.

6 Hamilton RC. Brain stem anaesthesia following retrobulbar block. Anaesthesiology 1985; 63: 688-90.

7 Follette JW, LoCascio JA. Bilateral amaurosis following unilateral retrobulbar block. Anaesthesiology 1985; 63: 237-8.

8 Wittpen JR, Rapoza P, Sternberg P, Kuwashima L, Saklad J, Patz A. Respiratory arrest following retrobulbar anaesthesia. Ophthalmology 1986; 93: 867-70

9 Javitt JC, Addiego R, Friedberg HL, Libonatti MM, Leahy JJ. Brain stem anaesthesia after retrobulbar block. Ophthalmology 1987; 94: 718-24.

10 Rosenblatt RM, May DR, Barsoumian K. Cardiopulmonary arrest after retrobulbar block. Am f Ophthalmol 1980; 90: 425-7.

11 Ahn JC, Stanley JA. Subarachnoid injection as a complication of retrobulbar anaesthesia. Am $f$ Ophthalmol 1987; 103: 225-30.

12 Cardan E, Pop R, Negruiriu S. Prolonged haemodynamic disturbances following attempted retrobulbar block. Anaesthesia $1987 ; 42$ : 668-9.

Rogers R, Orellana J. Cranial nerve palsy following retrobulbar anaesthesia. Br f Ophthalmol 1988; 72: 78 .

14 Elk JR, Wood J, Holladay JT. Pulmonary edema following retrobulbar block.

$\mathcal{F}$ Cataract Refract Surg 1988; 14: 216-7.
15 Ruusavaara P, Setala K, Taarkanan A. Respiratory arrest after retrobulbar Ruusavaara P, Setala K, Taarkanan A. Resp
block. Acta Ophthalmol 1988; 66: 223-35.

16 Zeitlin GL, Hobin K, Platt J, Woitoski N. Accumulation of carbon dioxide during eye surgery. F Clin Anaesth 1989; 1: 262-7.

17 Lee DS, Kwon NJ. Shivering following retrobulbar block. Can 7 Anaesth 1988; 35: $294-6$.

18 Rao VA, Kawatra VR. Ocular myotoxic effects of local anaesthetics. Can $\mathcal{f}$ Ophthalmol 1989; 23: 171-3.

19 Morgan GE. Retrobulbar apnoea syndrome; a case for the routine presence of an anaesthesiologist. Reg Anaesth 1990; 15: 107.

20 Rozanski A. Mental stress and the induction of silent myocardial ischemia in patients with coronary artery disease. New EnglF Med 1988; 318: 21.

21 Fisher SJ Cunningham RD. The medical profile of atart patients Geriatr Clin NAm 1985; 1: 339 .

22 College of Ophthalmologists and Royal College of Anaesthetists. Guidelines on local anaesthesia for ophthalmic procedures. 1993. 